\title{
Sincronicidades: história, memória e ficção em Ana Maria Machado e Griselda Gambaro
}

Em "Fantasma oculto: alguns segredos de quem escreve", publicado no livro de ensaios Balaio: livros e leituras (2007), Ana Maria Machado fala das "sincronicidades" ou coincidências surpreendentes que ocorrem na nossa vida diária ou, ainda, e mais especialmente, quando nos encontramos imersos na leitura de um texto e algo nele nos fala diretamente e de maneira muito particular. São "encontros" instantâneos que repercutem em nós - uma palavra, uma imagem, uma situação ou sentimento que parecem coincidir com algo que vivemos, sentimos ou apenas intuímos. Difíceis de serem explicadas, segundo a autora, as sincronicidades apontam para a existência de "uma espécie de dinâmica latente do texto" e revelam talvez "certas sintonias captadas na mesma onda" (Machado, 2007, p. 19) nas quais coincidem a pessoa que está lendo e o texto lido. Neste trabalho, discutirei algumas sincronicidades captadas na leitura dos romances $O$ mar nunca transborda (2008 [1995]), de Ana Maria Machado, e El mar que nos trajo (2001), da escritora argentina Griselda Gambaro.

Essas sincronicidades sucedem por estarem os dois romances sintonizados em uma "mesma onda" e suas autoras em um mesmo plano crítico-temporal: o de um presente consciente da importância de estabelecer-se e cultivar-se um diálogo constante com o passado, com a história. Meu propósito aqui é, portanto, o de examinar como Machado e Gambaro tecem um diálogo entre presente e passado, entre momento atual e história, a partir de uma primeira sincronicidade: em ambos romances, a interseção da história com $H$ maiúsculo e histórias/"estórias"; ou seja, a interseção da história com a memória e a ficção. Fundamentadas nessa interseção, as duas autoras traçam um retrato da nação enquanto põem em relevo questões relacionadas ao próprio conceito de nação e identidade nacional e à identidade do sujeito, isto é, à construção de uma subjetividade, armando tramas narrativas que entrelaçam a História, a memória e a ficção.

${ }^{1}$ Doutora em literaturas brasileira e hispano-americana e professora de espanhol e português na Washington and Lee University, Lexington, Virginia, Estados Unidos. E-mail: pintobaileyac@wlu.edu 
Ana Maria Machado, escritora consagrada pela crítica, ocupante da cadeira de número um da Academia Brasileira de Letras e bastante conhecida do público brasileiro, alcançou projeção internacional graças a seus livros dirigidos aos públicos infantil e juvenil, mas é autora de importantes obras de ficção para adultos, assim como de poesia e ensaios culturais e de crítica literária. Já a argentina Griselda Gambaro é um dos nomes mais destacados da moderna dramaturgia de língua castelhana, ganhadora de importantes prêmios literários e teatrais na Argentina e no exterior, e é também autora de inúmeros livros de contos e romances, além de, mais recentemente, livros dirigidos ao público infanto-juvenil. Em todas as suas obras, tanto a escritora brasileira como a argentina mostram um profundo engajamento crítico com a realidade de seus países - e de fato uma parte significativa da ficção e da dramaturgia de Gambaro aborda situações diretamente relacionadas à repressão política que a Argentina viveu na segunda metade do século XX, culminando com a ditadura militar de 1976-1983, a qual o governo ditatorial chamou eufemisticamente de Proceso de Reorganización Nacional. Também Machado trata em sua obra da ditadura militar brasileira iniciada com o golpe de estado de 1964, em particular em seu romance Tropical sol da liberdade (2005 [1988]). Aliás, as duas escritoras tiveram que se exilar devido à repressão e à censura em seus países durante as ditaduras militares, tendo Machado vivido na França e na Inglaterra de 1969 a 1972 e Gambaro na Espanha de 1977 a 1980.

Embora os romances $O$ mar nunca transborda e El mar que nos trajo tenham sido publicados após o restabelecimento de governos democráticos no Brasil e na Argentina, as duas obras refletem um esforço maior dessas duas sociedades em sanar o trauma político trauma individual e nacional - através da memória, um intento de debruçar-se sobre o passado para preservar a história, mesmo quando o discurso oficial ainda defendia uma política do esquecimento como forma de levar a nação de volta à "normalidade". No entanto, a memória, o ato de lembrar e testemunhar a história é, ao contrário, um poderoso instrumento para a conscientização da sociedade e para evitar que se repitam os erros do passado; tal como afirma a crítica norteamericana Amy Kaminsky em relação ao contexto latino-americano, o olhar sobre o passado responde à necessidade "de restabelecer uma comunidade nacional" destroçada pela ditadura e suas sequelas políticas, sociais e econômicas (Kaminsky, 1999, p. 21, tradução nossa). 
Relembrar e narrar vão servir não só como "barreira contra o esquecimento" (Machado, 2007, p. 55) e como instrumento de compreensão do passado político recente, mas também como meio de sanar uma ferida nacional e resgatar um sentido de cidadania e identidade. Portanto, outra sincronicidade: o retraçar que a memória faz da história através da ficção leva Ana Maria Machado e Griselda Gambaro (e com elas seus leitores) não só à história recente da repressão militar no Brasil e na Argentina, mas também a relembrar e a reescrever uma história mais distante, leva a um retorno às origens da nação e a outros períodos formadores da identidade nacional. Ademais, o narrar a história nacional através da ficção não só registra o passado para evitar que seja esquecido, como também proporciona um exame crítico do contexto histórico presente. Assim, e como veremos mais adiante, obras como os dois romances aqui discutidos narram o passado, "para contar uma história sobre o presente" (Kaminsky, 1999, p. 111, tradução nossa). Em um comentário sobre a dramaturgia de Gambaro que diz respeito também à sua ficção e à de Ana Maria Machado, Kaminsky afirma que "o jogo dialético entre o passado e o presente, entre aquilo que se encontra próximo e o que está longe..., funciona em uma simetria complexa na qual as distâncias no espaço e no tempo se permutam, de modo que a referência ao [...] presente é inequívoca" (Kaminsky, 1999, p. 111, tradução nossa).

A obra de Machado e a de Gambaro expressam uma profunda preocupação social e política, e representam um exercício crítico de procurar compreender e apreender, através da literatura, seus respectivos países e sociedades. Nos dois romances aqui discutidos, tal preocupação resulta em narrativas que inscrevem, escrevem e reescrevem identidades - a identidade do sujeito e a identidade nacional - a partir da interseção entre história, ficção e memória. $O$ mar nunca transborda e El mar que nos trajo recontam a história nacional do Brasil e da Argentina apresentando, cada um, uma visão particular da nação que destaca e valoriza a participação de determinados grupos no processo de construção nacional. Os dois romances narram a História nacional por meio de histórias de indivíduos cujas vidas decorrem às margens da historiografia oficial - a História com $\mathrm{h}$ maiúsculo que tende a representar a nação como uma entidade una com base em datas e eventos públicos e oficiais. Machado e Gambaro, ao contrário, problematizam o conceito da nação como uma entidade integrada e necessariamente coerente com a versão "oficial", preferindo enfatizar o 
que Homi Bhabha descreveu como sendo a "ambivalência que persegue o conceito de nação" (Bhabha, 1990, p. 1, tradução nossa).

Em O mar nunca transborda e El mar que nos trajo, Machado e Gambaro privilegiam a herança multiétnica e multicultural de seus países e reescrevem a narrativa nacional através de "narrativas menores", de pouca importância para a historiografia oficial, histórias de indivíduos e comunidades que viveram nos bastidores da história, ou seja, através das micro-histórias de segmentos da sociedade geralmente ausentes do quadro da história nacional, já que nesse quadro, em grande escala, privilegiam-se os nomes de heróis e generais, das grandes batalhas e acordos firmados, enquanto que a experiência dos "pequeninos" permanece irrelevante. Ao valorizar micro-histórias ocorridas à margem dos grandes eventos da história oficial, O mar nunca transborda e El mar que nos trajo caracterizam-se como exemplos da narrativa neo-historicista não incomum na virada do século XXI. Os personagens desse tipo de narrativa em geral não ocupam o papel de protagonistas da historiografia oficial, mas colocam-se "em relação dialética com situações políticas macro-históricas" (López Badano, 2006, p. 23, tradução nossa). Além disso, em O mar nunca transborda e El mar que nos trajo a história nacional é representada como um processo em andamento, como "história no processo mesmo do fazer histórico", nas palavras de Homi Bhabha (1990, p. 3, tradução nossa) - ou a história como cotidiano que se está vivendo. Entretanto, o processo histórico assim retratado só é concluído provisoriamente, através da leitura que cada nova geração de leitores faz do passado, das experiências, memórias e pós-memórias das gerações anteriores.

Pós-memórias, segundo conceituação desenvolvida por Marianne Hirsch, referem-se às memórias de eventos passados que nos chegam mediadas pela experiência de gerações anteriores. Hirsch desenvolve a noção de pós-memória em Family frames: photography, narrative, and postmemory (1997), "lendo" fotografias como narrativas da experiência judia durante o Holocausto. Ela afirma: "Desenvolvi esta noção em relação aos filhos de sobreviventes do Holocausto, mas creio que pode ser útil para descrever as memórias que uma segunda geração tem de eventos e experiências traumáticos vividos por uma cultura ou coletividade" (Hirsch, 1997, p. 22, tradução nossa). Em relação ao contexto latino-americano, e em particular aos romances de Machado e Gambaro aqui discutidos, o conceito de pós-memória é útil porque define uma 
conexão afetiva entre diferentes gerações, assim como o impacto que as experiências de gerações anteriores têm sobre as gerações atuais. E se Hirsch trabalha com textos visuais (fotografias) que narram histórias do passado, em $O$ mar nunca transborda e El mar que nos trajo as pós-memórias constituem recordações, histórias ("estórias") e tradições contadas em conversas íntimas e familiares. Calcadas na oralidade, apelam visualmente para a imaginação do ouvinte e, através da escrita de cada romance, mostram em cenas emblemáticas a experiência do passado e sua significação para o presente. Dessa maneira, a história nacional transforma-se em uma narrativa polifônica continuamente atualizada por quem a conta e por aqueles que a escutam e leem, enquanto que o conceito de identidade nacional adquire novos significados, vistos com base em perspectivas "menores" que levam à problematização de definições estabelecidas pelo discurso dominante do que é ser brasileiro, argentino ou mesmo latino-americano.

O mar nunca transborda e El mar que nos trajo são exemplos de narrativas historiográficas pós-modernas, segundo a conceituação de Linda Hutcheon (1991), e apresentam um exame crítico e revisionista do passado ao mesmo tempo que privilegiam perspectivas que não pretendem ser globais mas sim parciais e subjetivas. $\mathrm{O}$ olhar para $\mathrm{o}$ passado nacional possibilita também um olhar autorreflexivo, constituindo-se a história da nação em uma forma de espelho em que o sujeito pode ver-se refletido, desse modo possibilitando o delineamento de uma autoimagem. Como narrativas historiográficas, os dois romances demonstram mais ou menos explicitamente uma mesma preocupação histórica, embora cada um mantenha sua especificidade literária no recontar e reescrever a história nacional. Gambaro escreve uma narrativa breve, quase minimalista - embora abundante em lirismo e níveis de significação - e opta por apresentar poucas, porém contundentes, imagens emblemáticas da história argentina, em instantâneos de eventos históricos entrelaçados ao drama pessoal das personagens. Por exemplo, o início da Segunda Guerra Mundial é mencionado muito brevemente e somente no contexto do impacto que causou sobre os personagens: "Em 1939 estourou a guerra, e as viagens de Giovanni se interromperam. Durante a guerra, por esses anos, morreu Natália" (Gambaro, 2001, p. 150, tradução nossa).

Por sua vez, na nota "Aos leitores" que abre O mar nunca transborda, Machado afirma sua dívida para com historiadores como Sérgio 
Buarque de Hollanda, José Antônio Carvalho e Vilma Ferreira de Almada, em cujas obras a autora buscou dados sobre "a vida miúda e quotidiana de gente que não entra na História oficial, em lugares considerados sem importância por este Brasil afora" (Machado, 2008 [1995], p. 9) para, a partir desses dados, tecer um painel ficcional que servisse como registro alternativo da história nacional. Aí a imagem da nação aparece como "uma entidade em movimento que ademais pode não ter uma única figura mas sim tantas como sujeitos sociais que a experimentam e pensam", para usar as palavras do saudoso crítico peruano Antonio Cornejo Polar (1992, p. 140-141, tradução nossa).

A instabilidade do conceito de nação vem-se intensificando na nossa contemporaneidade - a mesma vivida pela protagonista de $O$ mar nunca transborda e pela narradora de El mar que nos trajo: uma contemporaneidade marcada pelo fluxo crescente de imigrantes, exilados e viajantes que continuamente atravessam fronteiras geopolíticas. Portanto, a nação é mais que nunca uma "entidade em movimento", como afirmou Cornejo Polar (1992), e tanto a identidade do sujeito como a imagem da nação são impactadas pelo deslocamento - espacial, temporal e cultural. Assim, o mar e o oceano, leitmotivs em ambos os romances, constituem metáforas multifacetadas tanto da experiência dos personagens, sujeitos deslocados pela migração e exílio, como do conceito de identidade nacional que cada obra projeta: uma identidade subjetiva e fluida, o que confere outra dimensão à famosa expressão de Benedict Anderson (1991) de que a nação é uma "comunidade imaginada". Nos romances de Machado e Gambaro, a nação e o sentido de identidade nacional que o sujeito adota são imaginados ou constituídos a partir da memória e das micro-histórias de gente que nunca chegou a protagonizar os grandes feitos da História. O mar será então a metáfora privilegiada para representar tanto o deslocamento do sujeito - suas des-raízes - como a imagem fluida da nação; símbolo das origens e de perdas; esperança de um recomeço e melhores condições de vida, mas também de morte e derrota; deslocamento, exílio, e a sempre presente possibilidade ou antecipação de um retorno à pátria. Sincronicidades, portanto, na visão "descentrada", "ex-cêntrica", que as duas autoras oferecem da nação, entendida não em seu espaço físico, limite político-geográfico, mas sim como comunidade imaginada e representada pelo tropo do mar, 
elemento fluido, fugidio, fascinante, entendendo fascínio como uma dialética de atração e repulsa.

$\mathrm{O}$ exílio, o deslocamento e o não pertencimento formam a experiência fundamental constitutiva da subjetividade dos personagens dos dois romances. O mar nunca transborda passa-se na década de 1990, e a protagonista, Liana, trabalha como jornalista para uma revista brasileira em Londres. O texto faz várias alusões à ditatura ainda recente e à situação social e econômica precária do país no período pósditatura, incluindo o caso do massacre da Candelária, quando um grupo de meninos de rua foi chacinado por policiais militares do Rio de Janeiro em julho de 1993, além de discutir a falta generalizada de direitos civis básicos entre a população mais carente. Muitas dessas alusões surgem nos diálogos que Liana tem com o namorado brasileiro, Tito, ele próprio ex-menino de rua que vendia bala para os motoristas parados nos sinais de trânsito, e explicam as razões por que tantos brasileiros abandonaram o país, preferindo encarar o deslocamento cultural e a marginalização social como imigrantes em outros países.

Para diminuir a saudade da terra natal e o sentimento de nãopertencimento, Liana recria a história de Manguezal, um vilarejo no litoral do Espírito Santo, desde os primeiros anos da colonização portuguesa, no século XVI. A história de Manguezal oferece uma microrrepresentação das origens da nação, assim como representa as origens da própria Liana, já que foi em Manguezal onde ela passou os anos de formação da infância. Aliás, em Liana encontram-se muitos traços autobiográficos da autora, sendo Manguezal uma representação fictícia de Manguinhos, cidadezinha no litoral do Espírito Santo onde Machado passou longos períodos da infância, na casa dos avós.

O mar nunca transborda apresenta, portanto, duas linhas narrativas paralelas, duas histórias em mis-en-abîme: uma, a história de Liana; e a outra, a história de Manguezal e seus habitantes, ou seja, a história do Brasil contada através das micro-histórias dos indígenas brasileiros, portugueses, africanos e, logo, de outros imigrantes e náufragos europeus que acabam assentando-se no litoral capixaba. A narrativa que Liana conta referente à história de Manguezal é de certa forma uma narrativa utópica da história e identidade nacional, na qual Manguezal representa um Éden terrestre onde indivíduos de origens e etnias diversas convivem em relativa harmonia e tranquilidade. Entretanto, $\mathrm{O}$ mar nunca transborda opõe-se aos romances fundacionais do século XIX, 
particularmente aos romances indigenistas de José de Alencar, pois não ignora a matriz africana formadora do perfil identitário brasileiro. Ao contrário, o romance de Ana Maria Machado procura destacar o papel histórico dos africanos na formação da identidade nacional. O texto privilegia uma perspectiva alternativa à dominante do conquistador branco, apresentando um amplo retrato da nação no qual sobressaem igualmente indígenas, africanos, europeus e, logo, em sua grande maioria, mestiços. A autora procura ressaltar não só os "pequeninos" da história e como a história nacional se faz do cotidiano sem importância dessa gente, mas também como a história nacional e a história do fazer cotidiano se misturam e afetam o dia a dia da gente comum (por exemplo, como a chegada de um pequeno grupo de marinheiros e soldados franceses põe em perigo as mulheres e as crianças de Manguezal e muda seu destino).

Além disso, a autora destaca a participação ativa das mulheres no processo histórico e na construção da identidade nacional. No romance, como em toda a ficção de Machado, as personagens femininas são mulheres fortes e determinadas; elas representam a figura materna geradora de uma nova nação mestiça, mas são também guerreiras e líderes a proteger a comunidade de invasores e exploradores. Entretanto, Machado mostra às vezes uma visão distinta da relação entre as raças. Por exemplo, a autora inverte o retrato tradicional da mucama negra, ama de leite do filho do senhor branco; aqui, temos, ao contrário, Marianita, uma dos personagens principais, filha de um colonizador português que se apaixona por um escravo africano e dele fica grávida.

Quando um feitor branco tenta violar Marianita, seu amante a protege, mas é assassinado pelo feitor, obrigando-a por sua vez a atacar o agressor e fugir. Marianita acaba na aldeia de Manguezal, onde dará à luz seu filho negro e amamentará ao mesmo tempo o bebê de uma mulher índia, morta por complicações no parto. Ela se transforma, assim, em uma "madona loura a se repartir entre um curumim da terra e um molecote africano" (Machado, 2008 [1995], p. 99). Mãe branca de filho negro e ama de leite de criança índia, Marianita exemplifica as mulheres fortes e decididas da ficção de Machado, mulheres que fazem seu próprio destino. No entanto, esse retrato de uma madona lusa como origem da nova raça brasileira não chega a recalcar a história de violações de mulheres índias e africanas que acompanhou a formação da nação brasileira. Em outras passagens, o romance registra o legado 
cruel da colonização e da escravidão, traçando, aliás, um paralelo entre a violência do passado colonial e escravista com a violência do Brasil contemporâneo: "Essa capacidade de violência brasileira, ali ao lado da festa e da alegria, sempre pronta para entrar em cena, é uma coisa que me espanta sempre. Falam tanto na nossa cordialidade, na nossa doçura, mas é só arranhar a casca e explode uma selvageria que não dá para entender" (Machado, 2008 [1995], p. 113).

A história de Marianita e de outros personagens da aldeia de Manguezal propõe-se como "uma arqueologia narrada" (Machado, 2008 [1995], p. 93) do vilarejo e, por extensão, do Brasil. Liana, a protagonista de $O$ mar nunca transborda, escreve uma nova narrativa fundacional da nação brasileira a partir da perspectiva de seu próprio deslocamento cultural em Londres. Liana representa o sujeito contemporâneo globalizado, "fronteiriço", a quem falta uma "ancoragem estável", no dizer de Stuart Hall (2006, p. 7). Deparando-se em Londres com a falta de um ponto de referência estável que pudesse apoiar e alimentar um "sentido de brasilidade", a protagonista recria suas origens e a história de seus antepassados em uma narrativa baseada na memória e nas histórias que escutou das avós e de outros membros da família. Suas fontes de informação, por conseguinte, não são documentos históricos oficiais mas sim as "estórias", micro-histórias passadas de geração em geração pela tradição oral, nas conversas familiares em torno da mesa do jantar. Daí emerge uma "comunidade imaginada", uma ideia de nação que incorpora símbolos, expressões e valores culturais e afetivos, e que se torna para a protagonista o ponto de referência, a âncora onde apoiar um sentido estável - embora não imutável - de identidade, o porto seguro para onde o sujeito descentrado e deslocado anseia retornar.

A ânsia do retorno, a nostalgia do mar, da terra natal e das origens são também leitmotivs em El mar que nos trajo, e a relação entre mar e memória é apontada já na epígrafe do livro, um fragmento de um poema do escritor italiano Salvatore Quasímodo em que se lê: "Eu queria ainda que a ti chegasse/ de mim um eco de memória,/ como o escuro murmúrio do mar" (Gambaro, 2001, p. 7, tradução nossa). No romance, fica sublinhada uma imagem dialética do mar, como símbolo de recomeço e esperança, mas também do mistério e incerteza do desconhecido. A narrativa inicia-se no ano de 1889, quando Agostino, um italiano de 19 anos, parte de Gênova para a América do Sul em um navio no qual encontra trabalho, e descreve eventos acontecidos na 
Argentina e na Itália até meados do século XX, após o término da Segunda Guerra Mundial. Desembarcando em Buenos Aires, Agostino apaixona-se por outra imigrante italiana e decide não retornar à terra natal. O casal encontra moradia em um cortiço, uma "casa de inquilinato", onde nasce uma filha, Natália, iniciando-se assim uma saga familiar que abarca os dois lados do Atlântico, já que Agostino é forçado a abandonar Natália e sua mãe para retornar à pátria, a Ilha de Elba, onde terá um filho com a esposa, que o esperava.

A saga familiar não chega a uma conclusão, mas alcança os dias de hoje através da figura da narradora, que relembra histórias contadas em volta de uma mesa de jantar. Essas histórias, memórias de infância e pós-memórias de gerações mais velhas, compõem a narrativa que temos em mãos: a saga continua na figura da narradora e em gerações futuras, bem como o processo de construção da identidade nacional. Cabe observar também que El mar que nos trajo, em suas esparsas 156 páginas, não é um exemplo típico do gênero saga familiar, pois Gambaro foge ao detalhe, preferindo mostrar momentos chave das vidas dos personagens que revelam de maneira inequívoca seu sentido de não pertencimento, isolamento e vulnerabilidade. Esses eventos, relatados a partir da perspectiva subjetiva dos personagens, permite à autora traçar em breves pinceladas o passar do tempo e a evolução da história, mostrando como pano de fundo eventos políticos de importância nacional e internacional, como o movimento anarquista do começo do século XX; o massacre de operários pela polícia e exército argentinos durante a chamada "Semana Trágica" de 1919; e o governo de Juan Perón: "José [...] não entendia como os operários podiam submeter-se a esse militar que vociferava dos balcões. Mentia como Mussolini e como Mussolini transformava direitos em favores ou esmolas. Deixaria um país arrasado" (Gambaro, 2001, p. 154, tradução nossa). Assim, a narrativa põe em relevo as consequências humanas em pequena escala de eventos históricos de impacto nacional ou global, enquanto que os poucos personagens ilustram a realidade de todo um segmento da sociedade que viveu experiências semelhantes de exclusão social, cultural e econômica.

Tal como Ana Maria Machado, Griselda Gambaro privilegia como fonte de informação histórica não a historiografia oficial, mas uma tradição oral íntima, pessoal. El mar que nos trajo registra o cotidiano dos imigrantes italianos e sua participação na formação da identidade nacional, enfocando 
principalmente a vida de várias gerações de mulheres e sua luta pela sobrevivência, desde as primeiras décadas do século $X X$ até o período imediatamente posterior ao final da Segunda Guerra Mundial. O retrato da nação que Gambaro apresenta não se encontra fundamentado no famoso Río de la Plata - onde teve início a exploração e colonização espanhola da região - nem em mitos nacionais promovidos pelo discurso oficial, mas sim no mar, no oceano, promessa de uma vida melhor para os imigrantes europeus pobres que se aventuravam a atravessá-lo. Entretanto, uma vez radicado o imigrante em Buenos Aires, o mar passa a estar associado à saudade da terra natal, à nostalgia de uma vida anterior que, vista através das brumas da memória, parece melhor e mais amena que a vida dura, oprimida pela pobreza que se encontra na capital argentina. Nesse ambiente opressivo, somente uma única coisa alivia o pesar de Agostino: a filha Natália, a quem apelida "barquita mía", ou "meu barquinho" (Gambaro, 2001, p. 31, tradução nossa), canalizando para ela o amor e a saudade que nutre pelo mar e pela ilha natal.

Gambaro resgata não só presença dos imigrantes italianos na história argentina, como também a história de sua própria família, já que seus pais eram também imigrantes saídos de Gênova para a América do Sul. A nostalgia do mar que Natália sente - embora nunca tivesse realmente visto mais que o porto de Buenos Aires, onde nascera - representa não só o desejo da personagem pelo pai ausente, como também a nostalgia das origens da própria autora, um desejo de reatar e fortalecer os laços com os antepassados italianos, cujo importante papel na formação da identidade argentina, embora indiscutível, permaneceu ignorado pelos anais da história. A narradora, que somente no último parágrafo do romance é identificada como sendo sobrinha de Natália, é o elo que une os eventos e personagens do passado ao período atual; ela serve como testemunha da vida dos que já se foram, contando e, assim, revivendo as memórias e pós-memórias de várias gerações da família.

El mar que nos trajo é, portanto, uma saga familiar que conta a história nacional a partir da ótica do imigrante socialmente marginalizado e da primeira geração de seus descendentes. Ao enfocar a experiência dos imigrantes italianos no novo país - suas lutas, miséria, marginalização e isolamento cultural e linguístico, já que muitos deles nunca chegaram a dominar o espanhol -, Gambaro contradiz a ideologia de uma "argentinidade" única, dominante na Argentina durante a primeira metade do século $\mathrm{XX}$, uma ideologia fundamentada no mito hegemônico 
do progresso e de grandes expectativas para toda a sociedade argentina (Cheadle, 2007, p. 13-14). No ensaio "Cities and identities at the turn of the twentieth century", Norman Cheadle sugere que essa visão mítica de uma identidade nacional integrada e grandiosa existente na primeira metade do século XX persiste até a época contemporânea, quando os argentinos deparam-se com a crise econômica, política e cultural provocada pela globalização. Segundo Cheadle, perante essa crise da pósmodernidade, intelectuais argentinos destacados como Beatriz Sarlo contrastam o esfacelamento contemporâneo da identidade nacional com "um sentido de identificação" nacional generalizado, que haveria sido possível no período moderno. Citando um conhecido ensaio de Sarlo, "Ya nada será igual", publicado na revista argentina Punto de vista (2001), Cheadle afirma: "Sarlo considera que, apesar de tudo, era possível um sentido de identidade nacional graças à alfabetização praticamente universal, aos direitos políticos e ao trabalho relativamente assegurado" (Cheadle, 2007, p. 15, tradução nossa).

A realidade vivida pelos personagens de El mar que nos trajo refuta totalmente essa ideia de cidadania e identidade nacional ao alcance de toda a população. O romance de Gambaro, muito pelo contrário, revela a marginalização e a opressão sofridas por aqueles que mal tinham o que comer, embora trabalhassem por muitas horas em condições subumanas e aguentassem o abuso e a exploração dos patrões e dos donos dos cortiços onde moravam, além da humilhação que a condição de imigrante e a barreira da língua lhes impunham. Natália, a mãe, a irmã, a família e os vizinhos representam assim um segmento da sociedade argentina que permaneceu excluído da imagem otimista da nação e da identidade nacional prevalente na primeira metade do século $X X$, imagem que na contemporaneidade é vista ainda com a nostalgia de tempos "melhores".

Dois temas recorrentes e fundamentais na obra de Gambaro, tanto na ficção como na dramaturgia, percorrem as páginas de El mar que nos trajo: as relações de poder e a violência - suas causas, manifestações e impacto sobre a vida da gente comum. Assim como nas obras em que Gambaro aborda o período de repressão militar das décadas de 1970 e 1980, em El mar que nos trajo os personagens são também vítimas das relações de poder e da violência que contaminam a vida diária, sofrendo a opressão consequente da pobreza, exploração econômica e exclusão social. Ao mesmo tempo, o tema da perda da 
liberdade de movimento e de expressão, recorrente em muitas das obras da escritora que enfocam a ditadura, reaparece aqui nos sofrimentos do imigrante, exilado da pátria, afastado do mar, limitado em sua expressão por não ter total controle do idioma castelhano.

No entanto, o que distingue esse romance de outras obras de Gambaro, em particular as de ficção, são o estilo e a linguagem. El mar que nos trajo perde a teatralidade e o elemento do absurdo e do grotesco que caracterizam outros livros da escritora e ganha um lirismo pungente e íntimo. Esta, aliás, é uma diferença notável entre o estilo de Gambaro nesse romance e o de Machado em O mar nunca transborda. Os dois textos representam um contar de histórias que escreve e inscreve uma identidade de mulher - a protagonista, Liana, em O mar nunca transborda, e a narradora sem nome de El mar que nos trajo -, pondo em destaque a experiência de linhagens femininas: no romance de Machado, uma linhagem que vem desde as origens da nação brasileira e inclui as três matrizes formadoras do perfil étnico brasileiro, assim como grupos imigrantes mais recentes; no romance de Gambaro, a linhagem da família de Natália, sua mãe, irmã e sobrinhas. Para dar expressão a essas experiências, Machado cria um estilo narrativo que é frequentemente exuberante, como ondas de imagens que se sucedem no movimento interminável das marés. Por exemplo:

Ela [Liana] se chegou sobre a coxa dele [Tito], roçando e apertando, banhando a carne com tantos sumos, a mão esquerda em sua orelha, a direita em seu pênis, de leve, muito sem pressa, deixando tudo vir a seu tempo, crescer até tomar todo o espaço, os cheiros aumentando, a quentura latejando, a pele guardando o sol, o sangue se expandindo, na moleza quente da estação, fruta madura a se abrir suculenta e fresca, mar se fechando apertado em volta do corpo que mergulha, ondas batendo ritmadas e se quebrando com força até sumirem na areia. Quando Ângelo entrava bem fundo em Marianita e vestia com ela sua nudez, como se a mulher fosse a pintura de sua pele, convertiam-se ambos em vagalhões das ressacas de março a romper-se nas pedras com estrépito, arfantes e sem peias (Machado, 2008 [1995], p. 135, grifos no original).

O leitmotiv do mar e outras imagens a ele relacionadas (banhar, mergulho, areia, vagalhões etc.) sublinham a sensualidade do ato sexual de Liana e Tito e, paralelamente, de Ângelo e Marianita, personagens da narrativa que Liana vai traçando. Já o estilo de Gambaro é mais contido, 
quase seco, refletindo a vida das personagens cuja labuta diária oferece poucas oportunidades de alegria e deixa pouca margem para a expressão de sentimentos. Nesse sentido, Natália simboliza bem a aspereza que as dificuldades do cotidiano imprimem ao caráter do imigrante. Como muitas mulheres em suas condições, ela não se permite relações de amizade ou amorosas e repudia o único e fugaz momento de desejo que vive:

[Natália] Retrocedeu e Nino avançou. Então ela se quedou imóvel, respirando com força. Percebeu seu cheiro, um cheiro de sabão, de tabaco, imperceptível de cal e madeira, intenso de suor e silêncio [...]. Sua boca entreaberta buscou a dela com uma ansiedade desesperada, como a de um menino queimando de sede. Mas ele não era um menino e sim um homem que ela sentia estremecer [...]. Histórias de abandono ela já tinha muitas. Esse pensamento lhe provocou uma aversão súbita e completa, uma dor profunda. Como se atrevia a ofendê-la? Esse beijo tinha um sabor mais amargo que o fel (Gambaro, 2001, p. 104, tradução nossa).

O desejo sexual, brevíssimo intervalo roubado a labuta e preocupações diárias, representa aqui um raro encontro entre seres humanos, entre corpos marcados por signos do cotidiano simples - do trabalho (cal, madeira, suor), do isolamento (silêncio) - e pela memória do pai e de outras rejeições e perdas sofridas tanto por Natália como por Nino, outro imigrante italiano.

Natália e os outros imigrantes de El mar que nos trajo, assim como Liana e os personagens de $O$ mar nunca transborda, são sujeitos deslocados, ex-cêntricos, já seja devido à migração ou exílio, já seja devido à posição marginal que ocupam no espaço social. Esse deslocamento, portanto, não se restringe àquele que atravessa fronteiras geopolíticas, mas ocorre mesmo nos limites políticos de um dado país, como consequência de opressão política e econômica ou de discriminação racial, de gênero ou de outras formas. Natália, Liana e outros representam uma subjetividade em movimento, conceito que nessas obras é salientado pela metáfora do mar oceano e outras imagens a ele associadas. Essas narrativas contam o impacto que o fluxo e o deslocamento geográfico e cultural têm sobre o sujeito vivendo em espaços diaspóricos. Para esse sujeito "fronteiriço" - digo-o porque com frequência ele ocupa um "entrelugar" cultural -, o cruzamento de fronteiras não é somente espacial - fronteiras geopolíticas -, pois é 
principalmente a travessia de fronteiras afetivas que tem lugar no espaço da memória e das pós-memórias. Nesse movimento duplo, a narrativa que conta a história desses indivíduos problematiza tanto o conceito de nação e identidade nacional como o sentido de identidade do próprio sujeito, deslocado, des-centrado.

No livro Relocating identities in Latin American cultures, Elizabeth Montes Garcés afirma que "as identidades não podem mais estar amarradas às fronteiras nacionais [...] e por isso devem ser encontradas num espaço cultural descentralizado" (2007, p. 8, tradução nossa). Desse modo, nos romances de Ana Maria Machado e Griselda Gambaro, o espaço da nação é também "ex-cêntrico"; ele deixa de ser um ponto geopolítico precisamente definido para tornar-se uma sucessão de pontos no espaço temporal da memória, atravessando geografias e gerações, aproximando o passado do presente. Entretanto, vale salientar uma vez mais que esse é um passado encontrado na memória, nas pós-memórias e nas micro-histórias, o que vale dizer, na ficção das lembranças, onde o sujeito, como Liana ou a narradora de El mar que nos trajo, arma sua compreensão a respeito do presente e delineia um sentido de identidade identidade nacional, identidade do eu. A identidade nacional que Gambaro e Machado reconfiguram é uma identidade escrita a partir de um processo de "insistente re-memoração" (Epps e Cifuentes, 2005, p. 41, tradução nossa): "Resgatar a memória", como afirma a voz narrativa em O mar nunca transborda (Machado, 2008 [1995], p. 43), é a proposta deste e do romance de Gambaro. Sincronicidades, portanto, que falam ao leitor contemporâneo a partir de um projeto comum articulado na interseção entre história, memória e ficção, mostrando uma vez mais que, quando a História apresenta lacunas ou emudece vozes, a literatura (histórias/"estórias") desempenha um papel importante no registro das vidas da gente "miúda", da gente "sem importância".

\section{Referências}

ANDERSON, Benedict (1991). Imagined communities: reflections on the origin and spread of nationalism. 2. ed. Rev. e aument. Londres, Nova York: Verso.

BHABHA, Homi (1990). Introduction: narrating the nation. In: BHABHA, Homi (Ed.). Nation and narration. Londres, Nova York: Routledge. 
CHEADLE, Norman (2007). Cities and identities at the turn of the twentieth century. In: MONTES GARCÉS, Elizabeth (Ed.). Relocating identities in Latin America. Calgary: University of Calgary Press.

CORNEJO POLAR, Antonio (1992). La “Invención" de las naciones hispanoamericanas. In: ZAVALA, Iris M. (Ed.). Discursos sobre la "invención" de América. Amsterdam: Atlanta: Rodopi.

EPPS, Brad; FERNÁNDEZ CIFUENTES, Luis (Eds.) (2005). Spain beyond Spain: modernity, literary history and national identity. Lewisburg: Bucknell.

MONTES GARCÉS, Elizabeth (2007). Introduction. In: identities in Latin American cultures. Calgary: University of Calgary Press.

GAMBARO, Griselda (2001). El mar que nos trajo. Buenos Aires: Norma.

HALL, Stuart (2006). A identidade cultural na pós-modernidade. 11. ed. Tradução de Tomaz Tadeu da Silva e Guacira Lopes Louro. Rio de Janeiro: DP\&A.

HIRSCH, Marianne (1997). Family frames: photography, narrative, and postmemory. Cambridge: Harvard University Press.

HUTCHEON, Linda (1991). A poetics of postmodernism: history, theory, fiction. New York: Routledge.

KAMINSKY, Amy (1999). After exile: writing the Latin American diaspora. Minneapolis: University of Minnesota Press.

LÓPEZ BADANO, Cecilia (2006). Autoarqueologización, minimalismo, "clean" realism: la novela de saga familiar del norte al sur de Latinoamérica, o de Ricardo Elizondo a Griselda Gambaro. Revista de literatura mexicana contemporánea, n. 31, p. 23-30.

MACHADO, Ana Maria (2005 [1988]). Tropical sol da liberdade. Edição especial. Introdução de Carlos Emílio Corrêa Lima. Rio de Janeiro: Nova Fronteira.

MACHADO, Ana Maria (2007). Balaio: livros e leituras. Rio de Janeiro: Nova Fronteira.

MACHADO, Ana Maria (2008). O mar nunca transborda. 2. ed. Rio de Janeiro: Nova Fronteira.

SARLO, Beatriz (2001). Ya nada será igual. Punto de vista, n. 70, p. 2-11, ago.

Recebido em junho de 2014.

Aprovado em outubro de 2014. 


\section{resumo/abstract}

\section{Sincronicidades: história, memória e ficção em Ana Maria Machado e Griselda Gambaro}

\section{Cristina Ferreira Pinto-Bailey}

Este artigo discute comparativamente os romances $O$ mar nunca transborda, de Ana Maria Machado, e El mar que nos trajo, de Griselda Gambaro, com o propósito de examinar a representação da identidade nacional e da identidade do sujeito através da interseção entre história, ficção e memória. As duas obras oferecem representações da nação alternativas àquelas da historiografia oficial, privilegiando as micro-histórias de indivíduos ou grupos marginalizados, deslocados ou "ex-cêntricos". Salienta-se aqui o que Homi Bhabha considerou a "ambivalência" do conceito da nação em oposição ao mito hegemônico da identidade nacional como una e integrada.

Palavras-chave: história, memória, nação, identidade nacional.

\section{Synchronicities: history, memory and fiction in Ana Maria Machado and Griselda Gambaro}

\section{Cristina Ferreira Pinto-Bailey}

This article analyzes the novels $O$ mar nunca transborda, by Ana Maria Machado, and El mar que nos trajo, by Griselda Gambaro, within a comparative frame, in order to exam the representation of national identity and self-identity through the intersection of history, fiction and memory. The two novels offer an alternative perspective of nation that privileges the micro histories of groups or individuals at the margins of the official historiography, and emphasizes the "ambivalence" of the concept of the nation (according to Homi Bhabha), as opposed to a hegemonic idea of nation that defines it as a unified entity.

Keywords: history, memory, nation, national identity. 